\title{
Surface modification of Aluminium alloy (7xxx series) by multipass friction stir processing
}

\author{
P K Mandal * \\ Department of Metallurgical and Materials Engineering, Amal Jyothi College of Engineering, Kanjirappally, Kerala \\ (State), India.
}

Global Journal of Engineering and Technology Advances, 2021, 06(02), 008-017

Publication history: Received on 26 December 2020; revised on 16 January 2021; accepted on 18 January 2021

Article DOI: https://doi.org/10.30574/gjeta.2021.6.2.0127

\begin{abstract}
Multipass friction stir processing (MP-FSP) is a solid-state surface modification technique, which was developed based on the simple principle of FSW. Aluminium plates were subjected to MP-FSP from 1 to 14 passes along the longitudinal direction with the specified process parameters such as rotational speed of $1000 \mathrm{rpm}$ and travel speed of $70 \mathrm{~mm} / \mathrm{min}$ and axial force of $15 \mathrm{kN}$. Subsequently, similar process parameters had followed by doublepass friction stir processing (DP-FSP) in order to help determine the effectiveness of multipass in creating high strength of aluminium alloys. Nowa-days extensive research had focused on various process parameters such as rotational speed, traverse speed, tool design on processing of aluminium alloys and proficiently enhanced material properties. This technique has considered mostly development of green technology, which is energy efficient and environment friendly technique. Experimentally proven that the Al-Zn-Mg-Sc alloys are characterized through OM, FESEM, DSC, SEM, TEM, and mechanical properties. The tensile strength and ductility of the MP-FSP specimen improved significantly to $122.48 \%$, and $42.55 \%$ respectively, but hardness decline to $4.84 \%$ as compared to DP-FSP. This is due to not only for refinement of cast dendritic structure and eliminate segregation in the as-cast alloy, but also to the refining of grains, such as the uniform distribution of $\mathrm{Al}_{3} \mathrm{Sc}$ and hardening precipitates. To aim of this research work is to mainly focusing on MP-FSP may enhance mechanical properties better than DP-FSP and useful for macroscale applications.
\end{abstract}

Keywords: Mechanical testing; MP-FSP; SEM and TEM analysis; Surface modification.

\section{Introduction}

The Al-Zn-Mg alloy (7xxx series) is a well-known high strength and heat-treatable alloy. The principal mechanism controlling the plastic behaviour of this alloy is precipitation hardening due to the interaction of precipitates with dislocation, and the efficiency with which the precipitates can inhibit the mobility of dislocations $[1,2]$. The efficiency depends on many factors, principally on the nature, size and distribution of the precipitates after an appropriate ageing treatment. In aluminium alloys (7xxx series), the $\mathrm{Zn} / \mathrm{Mg}$ ratio is considered most critical to deciding the type of precipitation reaction and phase that takes place, and a $\mathrm{Zn} / \mathrm{Mg}$ ratio of 2 is considered the critical value which forming $\eta$ and T phases [3-5]. Scandium (Sc) is limited soluble in aluminium in the solid state and supersaturated solid solution decomposes on ageing at elevated temperature, precipitating the $\mathrm{Al}_{3} \mathrm{Sc}\left(\mathrm{L} 1_{2}\right)$ phase. Therefore, significant improvement in properties has been found for Sc additions in the range 0.20 to $0.33 \mathrm{wt} . \%$ in studies alloys [6, 7]. Recently, a friction stir processing (FSP) technique designed by Mishra and Charit is used for microstructural modification of metallic materials. FSP is an effective method of grain refinement, proving more intense plastic deformation as well as higher strain rates than other severe plastic deformation (SPD) methods. Since solid-state FSP does not result in solute loss by evaporation and segregation by solidification, solute elements are homogeneously distributed in the processing zone

\footnotetext{
${ }^{*}$ Corresponding author: P K Mandal
}

Department of Metallurgical and Materials Engineering, Amal Jyothi College of Engineering, Kanjirappally, Kerala (State), India. 
[8-10]. In this study, it has optimized MP-FSP as well as DP-FSP for processing of aluminium alloys to locally manipulate the cast microstructure achieving grain refinement, porosity elimination, and second-phase homogenization [11-13]. It has established the mechanism of microstructure evolution and evaluated the resultant mechanical properties. MP-FSP introduces a large amount of dislocations in the work piece. The rearrangement or elimination of these dislocations reduces the internal energy of the system, which is the thermodynamic driving force for recrystallization. Grain refinement is an effective mean to improve the mechanical properties, therefore, proof strength of the friction stir processed materials. Thus, MP-FSP creates a fine-grained microstructure with dispersive distributed particles and predetermining high angle grain boundaries, features that are important for improved mechanical properties [14, 15]. This technique may ultimately cover the way for extensive structurally applications of fine-grained alloys. The present study is ultimately highlight on the microstructure evolution, improvement in fracture resistance and strength by MPFSP.

\section{Material and methods}

Table 1 Chemical composition of the 7xxx series of aluminium alloys (wt. \%).

\begin{tabular}{|l|l|l|l|l|l|l|l|l|}
\hline Alloy designation & $\mathbf{Z n}$ & $\mathbf{M g}$ & $\mathbf{S c}$ & $\mathbf{S i}$ & $\mathbf{F e}$ & Al & $\mathbf{Z n + M g}$ & $\mathbf{Z n} / \mathbf{M g}$ \\
\hline Alloy 1 & 6.47 & 1.54 & 0.33 & 0.19 & 0.21 & Bal. & 8.01 & 4.20 \\
\hline Alloy 2 & 6.70 & 2.80 & 0.20 & 0.02 & 0.04 & Bal. & 9.50 & 2.39 \\
\hline
\end{tabular}

The aluminium alloys were prepared by cast metallurgy route with pure Zn, pure Mg and Al-2wt.\% Sc master alloy. Basically, the high strength Al-Zn-Mg alloys (7xxx series) were developed by Sc inoculation effect in the melt. The muffle furnace had used to melt the alloys at $780 \pm 5^{\circ} \mathrm{C}$. The melting was performed in air by a mild steel mould to a plate shape $\left(200 \times 90 \times 8 \mathrm{~mm}^{3}\right)$ casting. The chemical composition was determined by inductively coupled plasma atomic emission spectroscopy (ICP-AES) and atomic absorption spectroscopy (AAS) methods and results are shown in Table 1. Then, the cast alloys were kept in room temperature for three days to natural ageing. After natural ageing treatment, alloys were further solution treated at $465^{\circ} \mathrm{C}$ for $1 \mathrm{~h}$, water quenched, and then followed by artificial ageing at $140^{\circ} \mathrm{C}$ for $6 \mathrm{~h}$. The cast plates were performed separately under MP-FSP as well as DP-FSP at a constant axial force of $15 \mathrm{kN}$ with a nonconsumable martensitic stainless steel tool and tool design is given in Table 2. The metallographic samples were sectioned perpendicular to the processing direction then cut into the small pieces for polishing. The mechanically polished samples had cleaned by water then dried and etched with modified Keller's reagent $(1 \mathrm{ml} \mathrm{HF}+1.5 \mathrm{ml} \mathrm{HCl}+$ $2.5 \mathrm{ml} \mathrm{HNO}_{3}+95 \mathrm{ml} \mathrm{H}_{2} \mathrm{O}$ ) for optical microscopy. An optical microscope was used to obtain different microstructure images (Model no.: LEICA DMI 5000M). The FESEM with EDS analysis (Model no.: QUANTA 200F, 30kV) was determined for grain boundary segregation and detecting minor Sc contains of aluminium alloys. The DSC (Differential scanning calorimetry) run was carried out of experimental samples for revealing semi-solid state precipitation and dissolution reactions by using a nitrogen atmosphere and a constant heating rate of $10^{\circ} \mathrm{C} / \mathrm{min}$ till $650^{\circ} \mathrm{C}(\mathrm{Model} \mathrm{no.:}$ EXSTAR TG/DTA 6300). Different stages of microstructures were investigated by TEM (Transmission electron microscopy) analysis. The TEM thin foil (80 to $100 \mu \mathrm{m})$ samples were prepared through polishing by fine emery papers and subsequently through conventional twin-jet electropolishing technique using a $30 \% \mathrm{HNO}_{3}+70 \% \mathrm{CH}_{3} \mathrm{OH}$ solution at $-20^{\circ} \mathrm{C}$ and 20V. A Vicker's macrohardness testing machine (Model no.: FIE VM50 PC) was used to measure the hardness across the processed zone with a $10 \mathrm{~kg}$. load and 15s dwell time with the average of six readings in each time. MP-FSP was continuously performed 14 times by moving in 35\% increments toward the advancing side with the constant tool rotation speed of $1000 \mathrm{rpm}$ and a traverse speed of $70 \mathrm{~mm} / \mathrm{min}$. The total FSP length was around $200 \mathrm{~mm}$ from the pin entry to the pin exit. Thus, experimental samples were collected separately from stirred zone through MP-FSP plate and DP-FSP plate. The tensile specimen having $26 \mathrm{~mm}$ gauge length, $4 \mathrm{~mm}$ width, $2.5 \mathrm{~mm}$ thickness and $58 \mathrm{~mm}$ length, and tested by Universal Testing Machine ( $25 \mathrm{kN}, \mathrm{H} 25, \mathrm{~K}-\mathrm{S}$, UK) with a cross head speed of $1 \mathrm{~mm} / \mathrm{min}$ as per ASTM standard (E-8/E8M-11 sub size). The tensile fracture samples were cut cross-sectionally and cleaned properly with acetone then analyzed using a SEM (Scanning electron microscopy) images. 
Table 2 FSP conditions and parameters.

\begin{tabular}{|l|l|}
\hline Items & Parameters \\
\hline Tool configuration & $\begin{array}{l}\text { Shoulder diameter } 20 \mathrm{~mm} \text {, pin diameter } 5 \mathrm{~mm} \text {, pin height } 3.5 \mathrm{~mm}, \\
2^{\circ} \text { tilt angle. }\end{array}$ \\
\hline Processing parameters & $\begin{array}{l}\text { Tool rotation speed } 1000 \mathrm{rpm} \text {, plate travel speed } 70 \mathrm{~mm} / \mathrm{min}, \\
\text { down-ward axial force } 15 \mathrm{kN} .\end{array}$ \\
\hline Processing direction & Clockwise and unidirectional. \\
\hline No. of passes and processing interval & MP-FSP and DP-FSP; 5 min rest in between two successive passes. \\
\hline
\end{tabular}
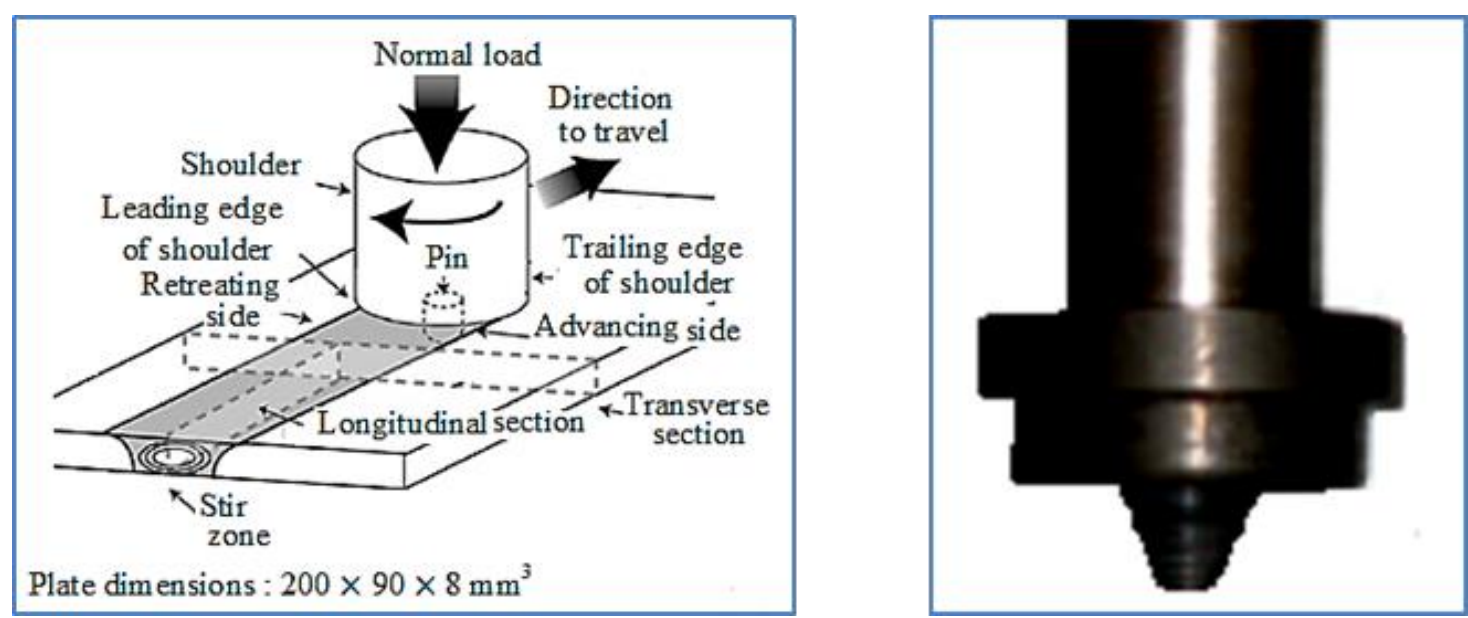

Figure 1 Illustration of FSP set-up and a tool configuration.

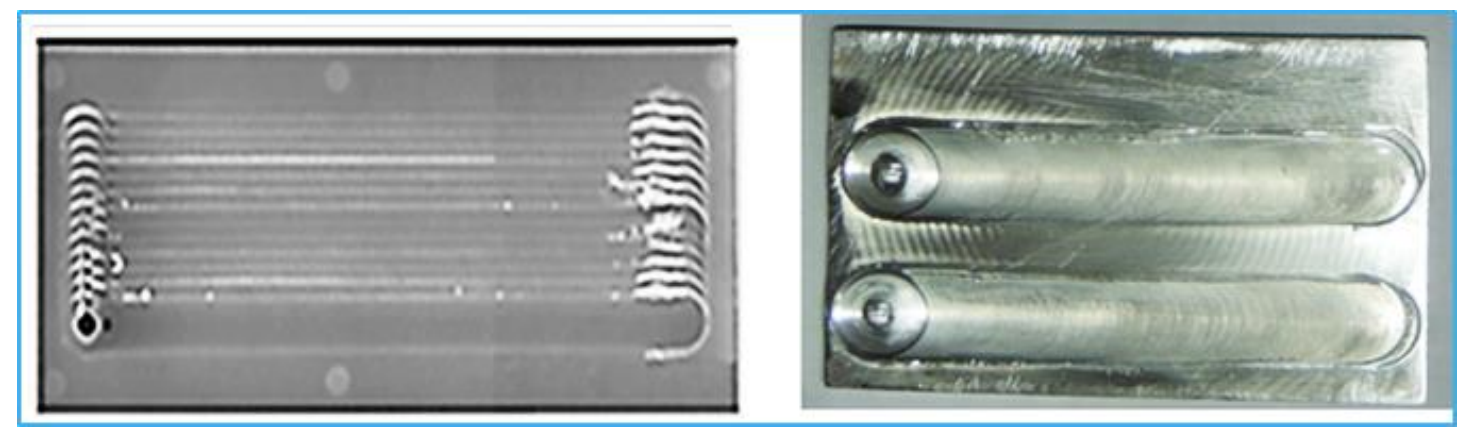

Figure 2 Illustration of macrographs of aluminium alloys: (a) Continual 14 passes of MP-FSP plate, and (b) Each processing zone contain two passes of DP-FSP plate.

\section{Results and discussion}

The important objective of FSP technique is to modify the microstructure of the aluminium alloy rather than conventional joining processes. The basic principle has been monitored by friction stir welding (FSW). The current study examines the effect of MP-FSP on aluminium alloys by adding one pass at a time to the total of 14 passes. One of the important parameter for repetitive MP-FSP tool rotational speed, which contribute to the heat input to refine microstructure of each consecutive passes at the same direction on the work piece. In between two passes at least 5 minutes rest for cooling due to avoid over burn of high thermal conductivity of aluminium alloys. Other, important parameters are tool design and traverse speed which is shown in Table 2. The base plate of $8 \mathrm{~mm}$ thick aluminium alloy was illustrated experimental set-up and stirring them together with a tool assembly by using vertical milling machine 
as shown in Figure 1. Investigation has indicated that in MP-FSP a continuous dynamic recrystallization phenomenon occurs due to the tool pin disruptive mechanical action and the frictional heat produced. This phenomenon can lead to comprehensive microstructural refinement of alloys. Increasing the number of passes during MP-FSP probably has controlled to occurrence of more dynamic recrystallization [16,17]. In most of the cases, the average hardness value of MP-FSP sample is increased many folds due to the decrease in particle size of insoluble dispersoids and fine grain size. Based on macro-structural characterization of grain and precipitation, four distinct zones have been identified through optical microscopy (OM) such as nugget zone or stir zone (SZ), thermomechanically affected zone (TMAZ), heat affected zone (HAZ), and base metal (BM) as shown in Figure 2. While heat input can be calculated through the following relationship, $q$ (heat input) $=2 \pi /(3 \mathrm{~s}) \times \mu \times \mathrm{p} \times \omega \times \mathrm{R}_{\mathrm{s}} \times \eta=2 \pi /(3 \times 1.17) \times 0.3 \times 15 \times 16.67 \times 0.01 \times 0.8=1.07 \mathrm{~kJ} / \mathrm{mm}, \mathrm{where} \mathrm{s}$ (traverse speed) $=1.17 \mathrm{~mm} / \mathrm{sec}$., $\mu=0.3, \mathrm{p}$ (normal force) $=15 \mathrm{kN}$, $\omega$ (rotational speed) $=16.67 \mathrm{rev}$. $/ \mathrm{sec}$., $\mathrm{R}_{\mathrm{s}}($ tool shoulder radius $)=0.01 \mathrm{~m}, \eta$ (heat transfer efficiency) $=0.8$. Hence, the low heat input $(1.07 \mathrm{~kJ} / \mathrm{mm})$ significantly pinning the grain boundary due to second phase particles, results obtained finer grains in the matrix [18, 19]. Figure 3(a,b) the optical microstructures revealed that the increasing in Sc contents (0.20-0.33 wt.\%), relatively fine microstructures $(\sim 2-6 \mu \mathrm{m})$ achieved due to $\mathrm{Al}_{3} \mathrm{Sc}$ particles dispersion in SZ during MP-FSP of Alloy 1.
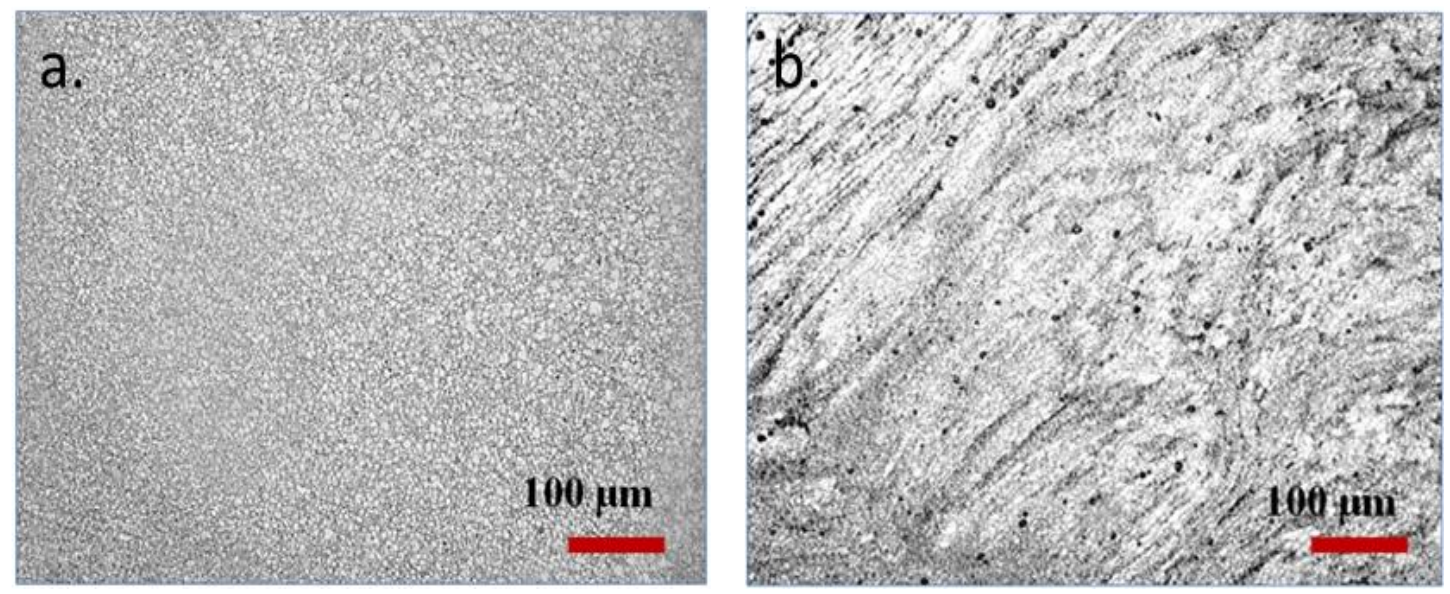

Figure 3 Optical micrographs of SZ (stir zone) aluminium alloys: (a) Alloy 1 (AC+MP-FSP condition), (b) Alloy 2 (AC+DP-FSP condition). (1000 rpm and $70 \mathrm{~mm} / \mathrm{min}$ )

In contrary, the optical microstructure revealed some small black spots possibly for Zn vaporization of high rotational speed as well as several flaws formed perhaps due to $\mathrm{Al}_{3} \mathrm{Sc}$ coarse particles or anti-recrystallization of coarse particles in the matrix during DP-FSP of Alloy 2 [20, 21]. In comparison, MP-FSP exhibited better grain refinement, and free of small black spots and flaws due to intermittent multipass processing which the material was allowed to cool back to room temperature after each pass and so on. The black spots and flaws are sealed due to each consecutive pass in the multipassing process. Figure 4 FESEM studies have been carried out to as-cast (AC) alloys which micrographs are exhibited grain boundary segregation, dendritic structures and inhomogeneity are main causes. EDS analysis identified high concentration of Sc (1.23 wt.\%) on the grain boundary as well as ample amount of Si (6.73 wt.\%) and Fe (2.96 wt.\%) contents for Alloy 1. The EDS analysis identified of Sc (0.51 wt.\%), and impurities like Si (0.22 wt.\%) and Fe (0.65 wt.\%) contents on the grain boundary for Alloy 2. It is also effectively proven by EDS analysis of high Zn contents $(\sim 7.18$ to $7.74 \mathrm{wt} . \%)$ in both of aluminium alloys. Figure 5(a) shows the DSC thermogram of $\mathrm{T}_{6}$ aluminium alloy. It has to indicated that both of DSC thermograms show similar features, it may indicating that Sc inoculation effects to the Al-Zn-Mg alloy does not change type of phase transformations. In the age-hardenable aluminium alloys, precipitation is an exothermic process, while their dissolution is an endothermic process. According to many investigations, the first exothermic peak $\left(250^{\circ} \mathrm{C}\right)$ can be exhibited to formation of $\eta$ and $\mathrm{Al}_{3} \mathrm{Sc}$ particles, and the endothermic peak starting from $550^{\circ} \mathrm{C}$ to $638^{\circ} \mathrm{C}$, corresponding to dissolution of $\eta$ and $\mathrm{Al}_{3} \mathrm{Sc}$ particles rather formation of $\eta$ phases, also indication of anti-recrystallization effect of $\mathrm{Al}_{3} \mathrm{Sc}$ particles as well as surface oxidation of Alloy 1. Figure 5(b) shows the DSC thermogram indicated first endothermic peak at $484^{\circ} \mathrm{C}$ due to dissolution of hardening phase $\eta$ with $\mathrm{Al}_{3} \mathrm{Sc}$ particles for low Sc $(0.2 \mathrm{wt} . \%)$ content, further softening of hardening phases continue upto $640^{\circ} \mathrm{C}$ but may further formation of overaged phases $\eta$ and their surface oxidation at $650^{\circ} \mathrm{C}$ [22]. Figure 6(a) shows TEM micrograph of as-cast (AC) aluminium alloy exhibited inhomogeneous, coarse grain and cauliflower shape $\mathrm{Al}_{3} \mathrm{Sc}$ (red arrows) particles in the matrix. The $\mathrm{Al}_{3} \mathrm{Sc}$ particles are mainly pinned on the grain boundary regions. Further, the dislocation lines and loops are also noticeable in the micrograph of Alloy 1. Figure 6(b) shows TEM micrograph of ascast (AC) aluminium alloy exhibited coarse, inhomogeneous and unmodified cast structure (red arrows) due to minor Sc (0.20 wt.\%) addition of Alloy 2. Figure 6(c) shows TEM micrograph of T6 ageing treated aluminium alloy is complex 
phenomenon and it enhances hardness due to minor Sc addition. The high hardness is achieved of $172 \mathrm{HV}$ due to optimum size, density of fine precipitates of $\mathrm{Al}_{3} \mathrm{Sc}$ (red arrows) and a large number of fine matrix strengthening $\eta$ precipitates (blue arrows) may be accelerated during T6 (140oC for 6h) ageing treatment of Alloy 2 [23].
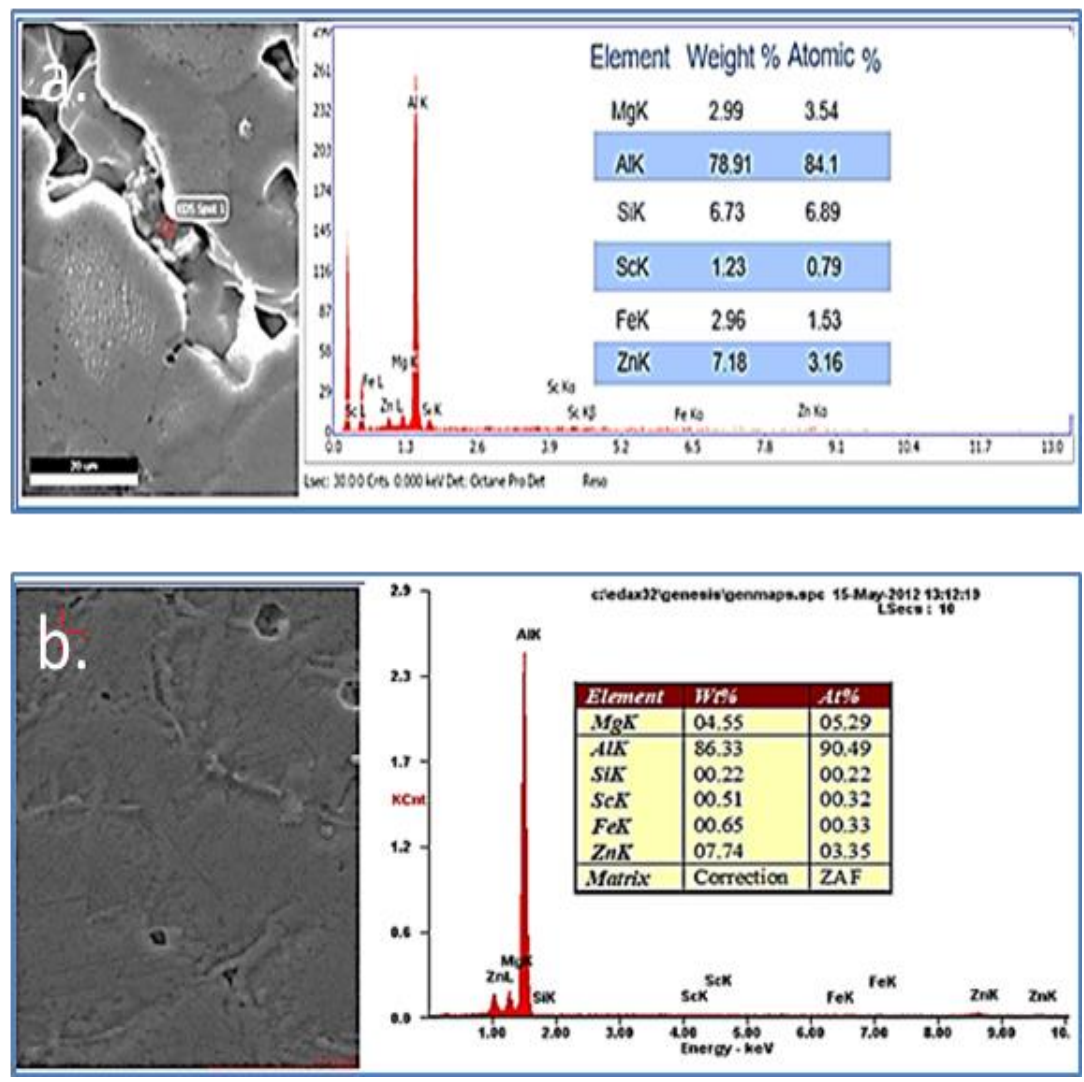

Figure 4 FESEM micrographs with EDS analysis of as-cast aluminium alloys: (a) Alloy 1, (b) Alloy 2.
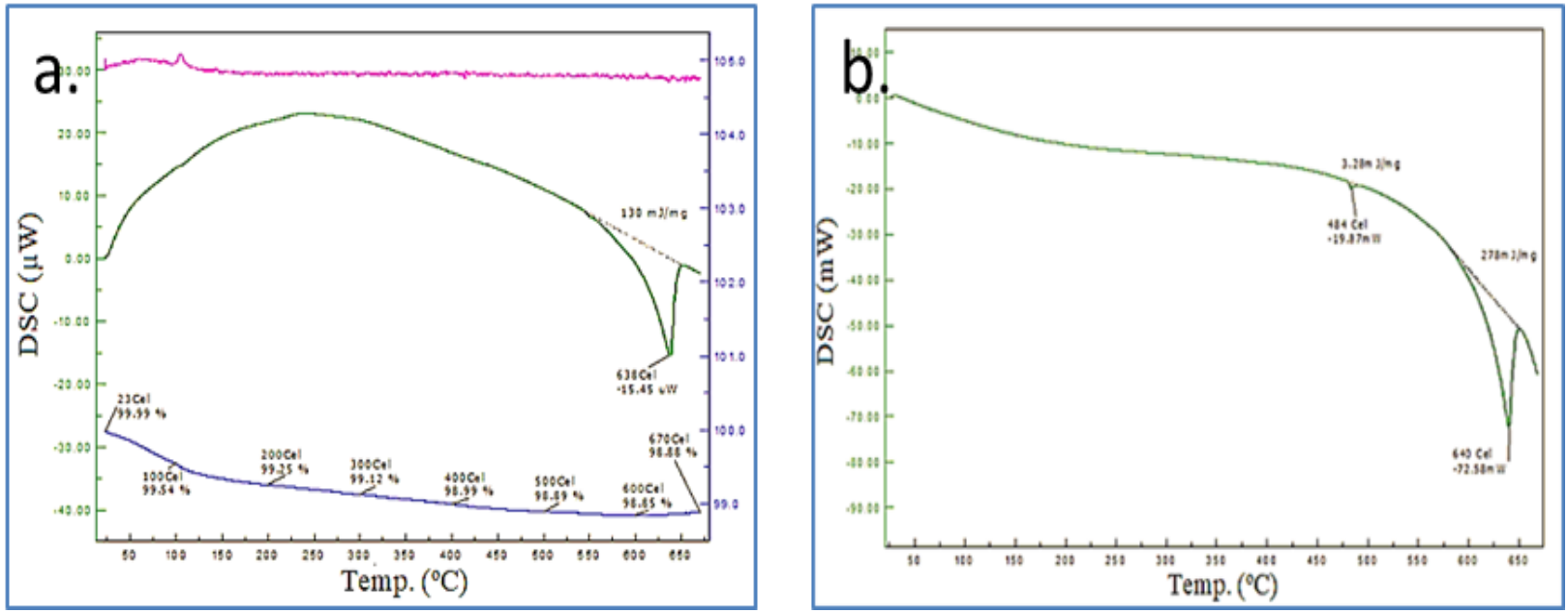

Figure 5 DSC thermograms of the aluminium alloys after aged at $140^{\circ} \mathrm{C}$ for $6 \mathrm{~h}\left(\mathrm{~T}_{6}\right.$ ): (a) Alloy 1, (b) Alloy 2.

Figure 6(d) shows TEM micrograph of SZ exhibited uniform $\mathrm{Al}_{3} \mathrm{Sc}$ precipitates (red arrows) which are fully coherent, well distributed and thermodynamically stable in the matrix. During DP-FSP generates intense plastic deformation and elevated temperature $400-500^{\circ} \mathrm{C}$, resulting in the formation of fine recrystallized grains with predominant high angle grain boundaries with fewer numbers of $\mathrm{Al}_{3} \mathrm{Sc}$ coarse particles and dislocations embedded in the grain boundary. The dispersion of fine precipitates are very effective pinning sites for the movement of grain and 
subgrain boundaries during the thermomechanical processing and inhibited recrystallization. Basically, two types of hardening particles are observed like rod shape $\eta$ phases and cauliflower type $\mathrm{Al}_{3} \mathrm{Sc}$ particles after post ageing treatment at $140^{\circ} \mathrm{C}$ for $2 \mathrm{~h}$ [24]. Figure 7 (a) shows SEM tensile fractograph exhibited ductile mode of feature throughout in the matrix after AC+MP-FSP of Alloy 1. It has indicated several spots (red arrows) with swallow depth inside some coarse particles perhaps for these second-phase particles agglomeration, its acting for stress concentration centre or crack propagation faster for low fracture strength in the matrix.
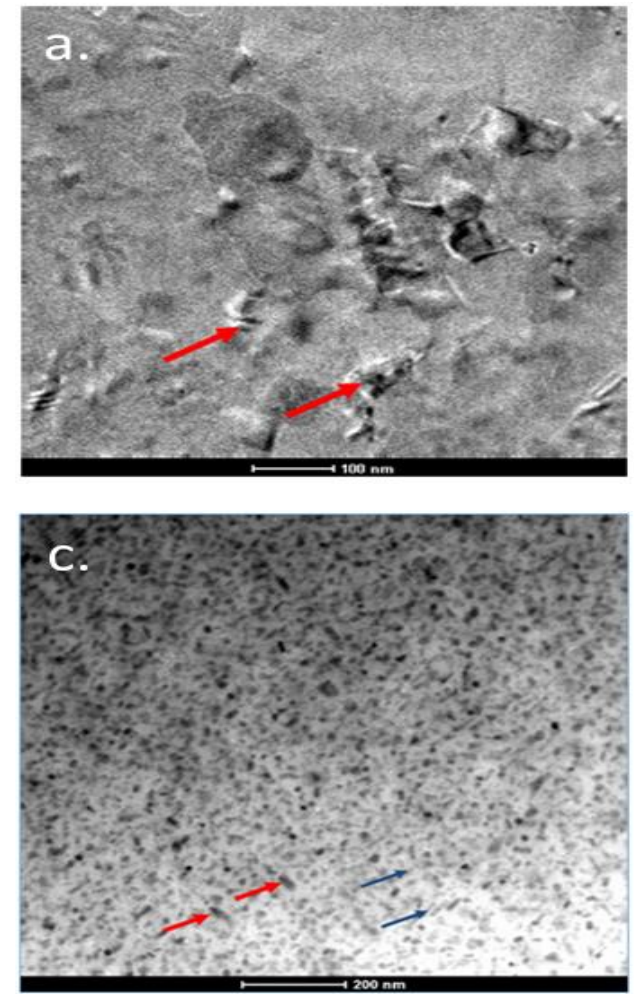
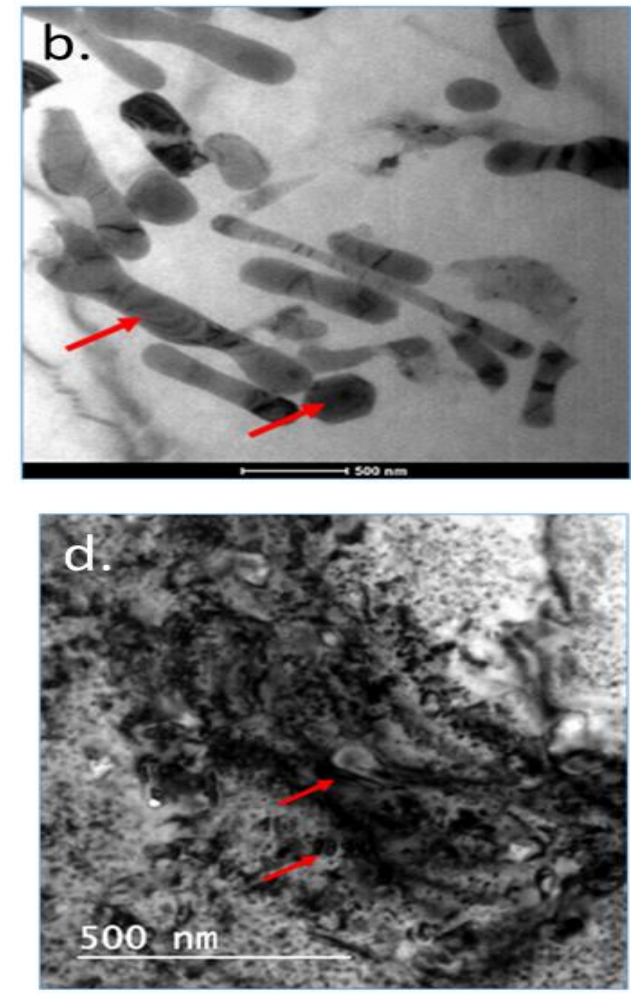

Figure 6 TEM micrographs of aluminium alloys as AC, after different heat treated and FSP condition: (a) Alloy 1 (AC), (b) Alloy 2 (AC), (c) Alloy 2 ( $\mathrm{T}_{6}$ ), and (d) Alloy 2 (AC+DP-FSP+Post ageing treatment at $140^{\circ} \mathrm{C}$ for $2 \mathrm{~h}$ ). (1000 rpm and $70 \mathrm{~mm} / \mathrm{min}$ )

Figure 7(b) shows SEM tensile fractograph indicated reasonably finer grains and ductile mode of feature throughout the matrix after AC+DP-FSP of Alloy 2. It can be clearly seen that coarse impurity particles or large $\mathrm{Al}_{3} \mathrm{Sc}_{\mathrm{C}} \mathrm{clusters}(\mathrm{red}$ arrows) exist on the fracture surface of this alloy. Figure 7(c) shows SEM tensile fractograph indicated ductile mode of feature throughout the matrix after AC+DP-FSP+Post ageing at $140^{\circ} \mathrm{C}$ for $2 \mathrm{~h}$ of Alloy 2 . The fracture surface of this alloy consists of micro voids and dimples with various sizes indicating ductile mode of failure. Some coarser precipitates available that may acts as the failure initiation sites as indicated by red arrows during tensile loading, and the large precipitate-to-precipitate distance results in the creation of deeper voids. Moreover, owing to good interfacial bonding between the dispersed $\mathrm{Al}_{3} \mathrm{Sc}$ particles and the matrix as confirmed by the presence of dimples, the ductility is enhanced with the limited or doublepass processing too [25]. Figure 8(a, b) shows the evolution of mechanical properties of as-cast (AC) aluminium alloys, at the different level of Zn content from 6.47 to $6.70 \mathrm{wt} . \% \mathrm{with}$ the effect of Sc additions relatively enhances the tensile properties and hardness of the aluminium alloys. It has to mentioned that the apparently concludes to the addition of Sc in the range of about 0.20 to 0.33 wt.\% is most effective for increase in properties of the Al-Zn-Mg alloys [26-28]. This may be shown for age-hardening effects and the formation of significant amount of $\mathrm{Al}_{3} \mathrm{Sc}$ particles in the matrix as shown in TEM micrographs (Figure 6) and SEM fractographs (Figure 7). In contrast, Alloy 1 have better mechanical properties than Alloy 2 that likely to PS increases to $103.57 \%$, UTS increases to $96.0 \%$, hardness increases to $14.29 \%$, and ductility increases to $20 \%$, respectively. It may be concluded that a considerable amount of proof strength (PS), ultimate tensile strength (UTS), ductility (\%), and hardness (HV) are increased for as-cast (AC) Alloy 1 in comparison to as-cast (AC) Alloy 2. Although the MP-FSP alloy to obtained fine grains, minimal porosities and eutectic networks were broken into fine particles and second phase particles uniformly distributed in the matrix. Specially, SZ grains were considerably refined because of the dynamic recrystallization and pinning effects of the dispersed particles tends to better mechanical properties relative to the DP-FSP alloy [29-31]. The best MP-FSP alloy has achieved, where the PS is increased by $250.86 \%$, UTS is increased by $122.48 \%$, and the ductility 
by $42.55 \%$, but hardness diminish by $4.84 \%$ as compared to the DP-FSP alloy. However, these results are indicated enormous technological importance since MP-FSP is repeatedly employed as a repair and surface modification method as well as in two dimensional joining in industrial applications.

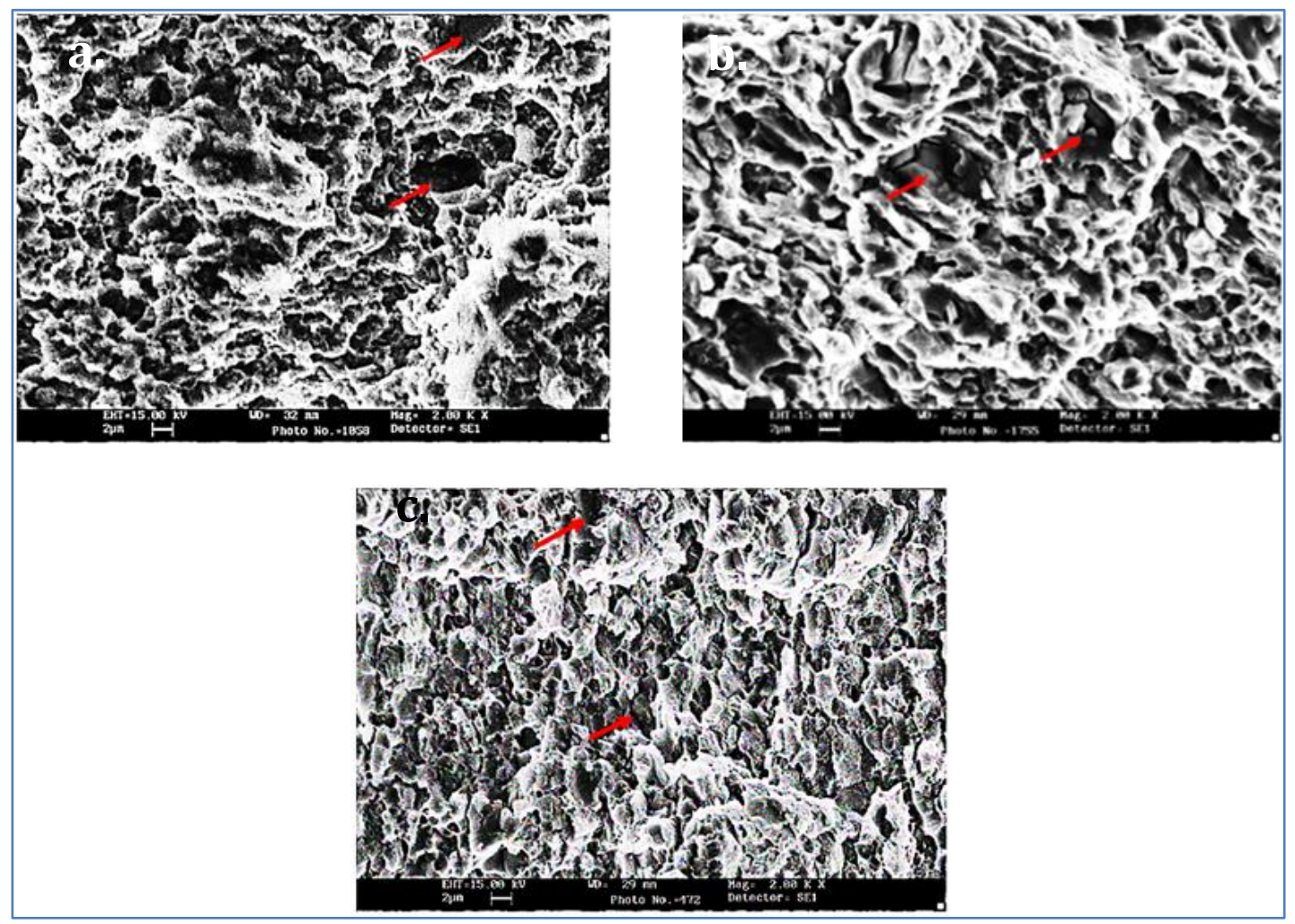

Figure 7 Illustration of SEM fractography after FSP conditions: (a) Alloy 1 (AC+MP-FSP condition), (b) Alloy 2 $\left(\mathrm{AC}+\mathrm{DP}-\mathrm{FSP}\right.$ condition), and (c) Alloy 2 (AC+DP-FSP+Post ageing at $140^{\circ} \mathrm{C}$ for $\left.2 \mathrm{~h}\right) \cdot(1000 \mathrm{rpm}$ and $70 \mathrm{~mm} / \mathrm{min})$
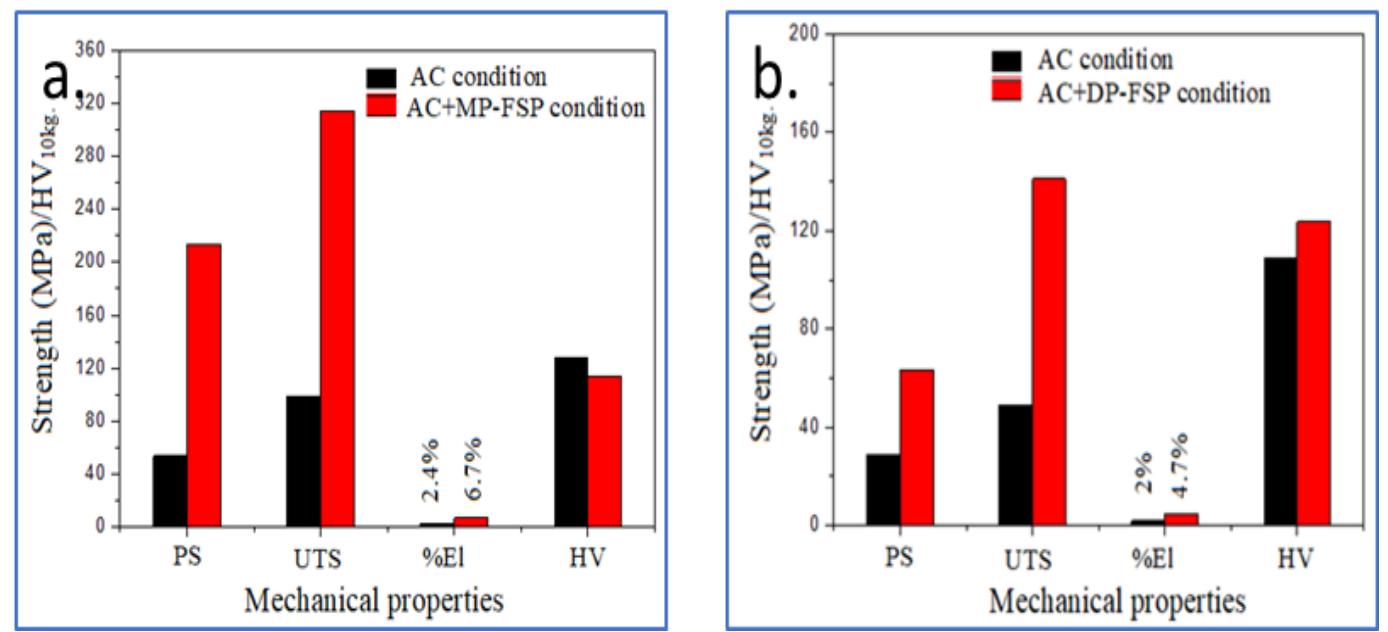

Figure 8 Bar diagrams are exhibited mechanical properties of aluminium alloys after different FSP conditions: (a) AC+MP-FSP for Alloy 1, (b) AC+DP-FSP for Alloy 2. (1000 rpm and $70 \mathrm{~mm} / \mathrm{min}$ )

\section{Conclusions}

- The friction stir process (FSP) makes an effective surface modification of aluminium alloys. Thus, higher ductility is due to the elimination of porosity and the disintegration of coarse second phase particles. The tensile 
strength after MP-FSP has been enhanced due to fine grains and homogenization of precipitate particles of aluminium alloys.

- The optical micrograph revealed fine grains owing to low heat input $(1.07 \mathrm{~kJ} / \mathrm{mm})$ during FSP, as refined grain size of 2-6 $\mu \mathrm{m}$ for Alloy 1 and 4-8 $\mu \mathrm{m}$ for Alloy 2 .

- The increase the formability in aluminium alloy is proportional to the increase in the material ductility that is attributed by the decrease in the grain size of the SZ. In contrast, the large numbers of black spots formed in SZ during DP-FSP, but it may be sealed by continual MP-FSP.

- $\quad$ DSC thermograms of the $\mathrm{T}_{6}$ aluminium alloys exhibiting many exothermic and endothermic peaks indicated the sequence of solid state reactions for the formation of $\eta$ and $\mathrm{Al}_{3} \mathrm{Sc}$ particles and their dissolution phenomenon.

- TEM micrograph of $\mathrm{T}_{6}$ aluminium alloy is complex phenomenon and it enhances hardness (172HV) due to minor Sc addition. While, TEM micrograph of SZ exhibited uniform $\mathrm{Al}_{3} \mathrm{Sc}$ precipitates (red arrows) which are fully coherent, well distributed and thermodynamically stable in the matrix.

- $\quad$ The MP-FSP has led to the enhance in the hardness of the alloys. Increasing the number of MP-FSP passes also led to the improvement of hardness. These can be attributed to the microstructural refinement due to mainly fine precipitates and $\mathrm{Al}_{3} \mathrm{Sc}$ dispersoids. However, tensile properties have enhanced due to age-hardening effect with fine dispersion of $\mathrm{Al}_{3} \mathrm{Sc}$ particles, and stirring effects.

- The SEM fractography of FSP alloy consists of micro-voids and dimples with various sizes indicating ductile mode of failure. Some coarser precipitates available that may acts as the failure initiation sites as indicated by red arrows during tensile loading, and the large precipitate-to-precipitate distance results in formation of dipper voids.

- The MP-FSP alloy had significantly higher tensile properties of $0.2 \%$ PS of $251.54 \%$ and UTS of $122.48 \%$ and a higher ductility of $42.55 \%$ and a lower hardness of $4.84 \%$ than DP-FSP alloy.

- The strength and hardness data indicates that decomposition must have resulted predominantly by precipitation of coherent $\mathrm{Al}_{3} \mathrm{Sc}$ precipitates but discontinuous precipitation caused in some coarsening of these precipitates. Although, SZ exhibiting a homogeneous and fine equiaxed grains due to dynamic recrystallization of highly deformed grains during MP-FSP.

\section{Compliance with ethical standards}

\section{Acknowledgments}

The author is very much grateful to Ministry of Human Resource Development (MHRD) Fellowship for financially support to carried out of research work in the Department of Metallurgical and Materials Engineering, Indian Institute of Technology Roorkee (IITR), Uttarakhand, India.

\section{Disclosure of conflict of interest}

There is no conflict of interest.

\section{References}

[1] Li XZ, Hansen V, Gjonnes J, Wallenberg LR. HREM STUDY AND STRUCTURE MODELING OF THE $\eta$ PHASE, THE HARDENING PRECIPITATES IN COMMERCIAL Al-Zn-Mg ALLOYS, Acta Metallurgica. 1999; 47(9): 2651-2659.

[2] Clinch MR, Harris SJ, Hepples W, Holroyd N. J. H., Lawday M. J., Noble B., Influence of Zinc to Magnesium Ratio and Total Solute Content on the Strength and Toughness of 7xxx series Alloys, Materials Science Forum. 2006; 519521: 339-344.

[3] Afify N, Gaber A-F, Abbady G. Fine Scale Precipitates in Al-Mg-Zn Alloys after Various Aging Temperatures, Materials Sciences and Applications. 2011; 2: 427-434.

[4] Deng Y, Yin Z, Zhao K, Duan J, He Z. Effects of Sc and Zr microalloying additions on the microstructure and mechanical properties of new Al-Zn-Mg alloys, Journal of Alloys and Compounds. 2012; 530: 71-80.

[5] Mukhopadhyay AK. Microstructure and properties of high strength aluminium alloys for structural applications, Transactions of The Indian Institute of Metals. April 2009; 62: 113-122.

[6] Wu L-M, Seyring M, Rettenmayr M, Wang W-H. Characterization of precipitate evolution in an artificially aged AlZn-Mg-Sc-Zr alloy, Materials Science and Engineering A. 2010; 527: 1068-1073. 
[7] Zhenbo H, Zhimin Y, Sen L, Ying D, Baochuan S. Preparation, microstructure and properties of Al-Zn-Mg-Sc alloy tubes, Journal of Rare Earths. Aug. 2010; 28(4): 641-646.

[8] Ma ZY, Friction Stir Processing: A Review, Metallurgical and Materials Transactions A. March 2008; 39A: 642658.

[9] Zhao YH, Liao XZ, Jin Z, Valiev RZ, Zhu YT. Microstructures and mechanical properties of ultrafine grained 7075 $\mathrm{Al}$ alloy processed by ECAP and their evolutions during annealing, Acta Materialia. 2004; 52: 4589-4599.

[10] Kwon Y-J, Shigematsu I, Saito N. Production of Ultra-Fine Grained Aluminium Alloy using Friction Stir Process, Materials Transactions. 2003; 44(7): 1343-1350.

[11] Johannes LB, Mishra RS. Multi passes of friction stir processing for the creation of superplastic 7075 aluminium, Materials Science and Engineering A. 2007; 464: 255-260.

[12] Esmaily M, Mortazavi N, Osikowicz H, Hindsefelt H, Svensson JE, Halvarsson M, Thompson GE, Johansson LG. Influence of Multi-Pass Friction Stir Processing on the Corrosion Behaviour of an Al-Mg-Si Alloy, Journal of The Electrochemical Society. 2016; 163(3): 125-130.

[13] Ku M-H, Hung F-H, Lui T-S, Chen L-H, Chiang W-T. Microstructural Effects of Zn/Mg Ratio and Post Heat Treatment on Tensile Properties of Friction Stirred Process (FSP) Al-xZn-yMg Alloys, Materials Transactions. 2012; 53(5): 995-1001.

[14] Surekha K, Murty BS, Prasad RK. Microstructural characterization and corrosion behavior of mulipass friction stir processed AA2219 aluminium alloy, Surface \& Coatings Technology. 2008; 202: 4057-4068.

[15] Su J-Q, Nelson TW, Sterling CJ. Microstructure evolution during FSW/FSP of high strength aluminium alloys, Materials Science and Engineering A. 2005; 405: 277-286.

[16] Liu FC, Ma ZY. Achieving high strain rate superplasticity in cast 7075Al alloy via friction stir processing, Journal of Materials Science. 2009; 44: 2647-2655.

[17] Ju X, Zhang F, Chen Z, Ji G, Wang M, Wu Y, Zhong S, Wang H. Microstructure of Multi-Pass Friction-Stir-Processed Al-Zn-Mg-Cu Alloys Reinforced by Nano-Sized $\mathrm{TiB}_{2}$ Particles and the Effect of $\mathrm{T}_{6}$ Heat Treatment, Metals. 2017; 7, 530: 1-15.

[18] Kumar A, Gautam SS, Kumar A. HEAT INPUT \& JOINT EFFICIENCY OF THREE WELDING PROCESSES TIG, MIG AND FSW USING AA6061, International Journal of Mechanical Engineering and Robotics Research. Jan. 2014; 1(1): 89-94.

[19] Charit I, Mishra R. S., Evaluation of microstructure and superplasticity in friction stir processed $5083 \mathrm{Al}$ alloy, Journal of Materials Research. Nov. 2019; 19(11): 3329-3342.

[20] Mandal PK. Investigation of Microstructure And Mechanical Properties of Al-Zn-Mg and Al-Zn-Mg-Sc Alloys After Double Passes Friction Stir Processing, International Journal of Materials Science and Engineering. June 2017; 5(2): 47-59.

[21] El Rayes MM, El Danaf EA, Soliman MS. High-temperature deformation and enhanced ductility of friction stir processed-7010 Aluminium Alloy, Materials and Design. 2011; 32: 1916-1922.

[22] Rout KK, Ghosh MM, Ghosh KS. Influence of Aging Treatments on Alterations of Microstructural Features and Stress Corrosion Cracking Behavior of an Al-Zn-Mg Alloy, Journal of Materials Engineering and Performance. July 2015; 24(7); 2792-2805.

[23] Wu L-M, Wang W-H, Hsu Y-F, Trong S. Effects of homogenization treatment on recrystallization behavior and dispersoid distribution in an Al-Zn-Mg-Sc-Zr alloy, Journal of Alloys and Compounds. 2008; 456: 163-169.

[24] Gholami S, Emadoddin E, Tajally M, Borhani E. Friction stir processing of 7075 Al alloy and subsequent aging treatment, Transactions of Nonferrous Metals Society of China. 2015; 25: 2847-2855.

[25] Ludtka GM, Laughlin DE. The Influence of Microstructure and Strength on the Fracture Mode and Toughness of 7XXX Series Aluminium Alloys, Metallurgical Transactions A. March 1982; 13A: 411-425.

[26] Deng Y, Ye R, Xu G, Yang J, Pan Q, Peng B, Cao X, Duan Y, Wang Y, Lu L, Yin Z. Corrosion behaviour and mechanism of new aerospace $\mathrm{Al}-\mathrm{Zn}-\mathrm{Mg}$ alloy friction stir welded joints and the effects of secondary $\mathrm{Al}_{3} \mathrm{Sc}_{\mathrm{x}} \mathrm{Zr}_{1-\mathrm{x}}$ nanoparticles, Corrosion Science. 2015; 90: 359-374.

[27] Reddy AC, Rajan SS. Influence of ageing, inclusions and voids on ductile fracture mechanism in commercial Alalloys, Bulletin of Materials Science. Feb 2005; 28(1): 75-79. 
[28] Kumar N, Mishra RS. Ultrafine-Grained Al-Mg-Sc Alloy via Friction-Stir Processing, Metallurgical and Materials Transactions A. Feb. 2013; 44A: 934-945.

[29] Kumar PV, Reddy GM, Rao KS. Microstructure, mechanical and corrosion behavior of high strength AA7075 aluminium alloy friction stir welds- Effects of post weld heat treatment, Defense Technology. 2015: 1-8.

[30] Sivaraj P, Kanagarajan D, Balasubramanian V. Effect of post weld heat treatment on tensile properties and microstructure characteristics of friction stir welded armour grade AA7075-T651 aluminium alloy, Defense Technology. 2014; 10: 1-8.

[31] Cavaliere P, Squillace A. High temperature deformation of friction stir processed 7075 aluminium alloy, Materials Characterization. 2005; 55: 136-142. 